\title{
HISTORIA DE LA CIRUGÍA ENDOSCÓPICA
}

\author{
HISTORY OF ENDOSCOPIC SURGERY
}

Luz Adriana García-Luengas ${ }^{1}$, Natali Contreras-Figueroa ${ }^{2}$, Iván Camilo González-Burgos ${ }^{1}$, Fabio Andrés

Morales-Espinosa ${ }^{1}$, Laura Isabel Narváez-Sierra ${ }^{3}$, Laura Jimena Useche-Pérez ${ }^{4}$, Juan Pablo Ruiz-Pineda ${ }^{5}$

1. Estudiante de XIII Semestre de Medicina. Integrante Semillero de investigación en Cirugía General. Fundación Universitaria Sanitas.

2. Estudiante de IX Semestre de Medicina. Integrante Semillero de investigación en Cirugía General. Fundación Universitaria Sanitas. 3. Médico General. Integrante Semillero de investigación en Cirugía General. Fundación Universitaria Sanitas.

4. Estudiante de XII Semestre de Medicina. Integrante Semillero de investigación en Cirugía General. Fundación Universitaria Sanitas

5. Médico Especialista en Cirugía, Clínica Colsanitas S. A. Docente Facultad de Medicina y Coordinador del Semillero de Investigación en Cirugía General, Fundación Universitaria Sanitas.

Esta nota de medicina se construyó en el marco del $1^{e r}$ encuentro de jóvenes semilleros, realizado el 7 de noviembre en la ciudad de Bogotá, por la Fundación Universitaria Sanitas

DOI: https://doi.org/10.26852/01234250.59

La Cirugía Laparoscópica (CL) es una técnica quirúrgica caracterizada por ser mínimamente invasiva, con el fin de resolver el origen quirúrgico causando el menor trauma posible en el paciente, brindando una pronta recuperación y ofreciendo una manipulación de órganos más precisa y cuidadosa. Así mismo, reduce el sangrado, produce mejores resultados estéticos y Disminuye el tiempo de estancia hospitalaria. Dentro de sus usos destaca su capacidad diagnóstica y terapéutica (la cual se puede realizar en un solo tiempo quirúrgico) y su versatilidad, ya que puede adaptarse a distintos procedimientos en distintas cavidades y espacios corporales (craneoencefálica, torácica, abdominopélvica, pared abdominal, entre otras) (1).

Aunque esta técnica ofrece una gran cantidad de beneficios, puede llevar a la generación de complicaciones tales como enfisema subcutáneo, neumotórax, síndrome compartimental e incluso el riesgo de conversión a técnica abierta. Varios estudios realizados teniendo como base procedimientos realizados tanto por vía abierta como por laparoscopía, por ejemplo la apendicectomía, refieres que la CL está asociada con una disminución del riesgo de infección del sitio operatorio (OR: 0,37 IC95\% 0,32-0,43) y con una disminución de la infección órgano espacio (para cirugías de bajo riesgo -laparoscopia vs laparotomía- 0,3 vs 0,4 y para alto riesgo 8,9 vs 12,3$)(2,3)$. Un situación similar se presenta para la colecistectomía, en donde se ha demostrado que la CL reduce la morbimortalidad, el número de días de estancia hospitalaria, procesos neumónicos e infecciones de sitio operatorio (4). 


\section{SIGLO XIX Y XX}

En el año 1804, el médico Philipp Bozzini inventó el primer endoscopio. Este instrumento constaba de una óptica, una fuente luminosa (en ese tiempo "luz de vela”) y un cuerpo que se adaptada entre estas dos estructuras según la abertura corporal que se necesitaba. La primera exploración que se realizó fue la cistostomía y posterior a esto inició a realizar procedimientos más complejos como fueron la extracción de cuerpos extraños, histerectomías transvaginales y exploraciones de la cavidad abdominal en pacientes con trauma. Posterior a esto, el urólogo Antonin Jean Desormeaux modificó dicho endoscopio y mejoró la luz adaptando una lámpara que requería petróleo y alcohol para dar mejor luminosidad. Años después Maximilian Nitze le agregó al endoscopio un lente para observar mejor las estructural en las cavidades (5).

El médico George Kelling se interesó por el estudio de las hemorragias gastrointestinales que ocurrían cuando se realizaban laparotomías. Es por esta razón que realizó una incisión en la pared abdominal por donde introdujo el endoscopio y utilizó un insuflador manual para generar presión intraluminal (de 50 $\mathrm{mmHg}$, generando un neumoperitoneo que lo ayudaba a disminuir la hemorragia y observar de mejor forma los órganos intraabdominales. Esta fue la primera celioscopía que se realizó con éxito, lo cual llevó a realizar diversas cirugías por laparoscopia. Kelling descubrió que, a pesar de que se desconocía la fisiopatología que el neumoperitoneo podría generar en el organismo, esta técnica quirúrgica representaba menos riesgos que una laparotomía y que la inserción del primer trocar en la cavidad abdominal debía ser ingresado en un ángulo de $45^{\circ}$ para no causar daño en las vísceras abdominales (5).

El Dr. Hans Christian Jacobeaus logró explorar la cavidad abdominal de un humano mediante técnica laparoscópica, gracias a que habían experimentado hacer el mismo procedimiento en un perro durante 1901. Con el pasar de los años dicha técnica se fue perfeccionando, aunque también se manifestaban sus limitaciones, razón por la cual solo era utilizada como último recurso diagnóstico, mayormente en patologías de origen gastrointestinal, ginecológico y torácico. Finalmente en 1933, se logró hacer una intervención quirúrgica, la primera lisis de adherencias intra abdominal laparoscópica. Más adelante, el británico Harold Hopkins inventó el endoscopio flexible en 1942, desatando una ola de innovación en técnicas quirúrgicas (para explorar las vías biliares y pancreáticas, para la realización de apendicectomías e incluso permitir la recuperación de óvulos) (6).

Simultáneamente, ocurrieron varios descubrimientos como la incorporación de la biopsia y el perfeccionamiento en el uso del neumoperitoneo para evitar sus efectos negativos en los pacientes. En el año 1965, el dúo de Keith Rabinov y Morris Simon lograron por primera vez una canulación exitosa de la papila de Vater, con esto dando origen a la Colangiopancreatografía retrógrada endoscópica (CPRE), procedimiento que hoy sigue siendo muy útil para el diagnóstico y tratamiento de los pacientes con obstrucción de la vía biliar. A finales de siglo, el ultrasonido fue introducido en el ámbito médico fortaleciendo la técnica laparoscópica, inicialmente en cuanto al diagnóstico, pero gracias a este avance hacia los años 90 se consiguió realizar abordajes terapéuticos como el drenaje de pseudoquistes pancreáticos (6).

En 1986 la cirugía laparoscópica integró el uso de videocámaras, logrando así amplificar y proyectar imágenes. Ya finalizando los 90, se desarrollaron lentes de aumento, fibra óptica y sistemas endoscópicos 3D, hechos importantes porque fueron el fundamento para la creación de los primeros equipos robóticos utilizados en el campo quirúrgico $(5,6)$.

\section{SIGLO XXI}

La creación de técnica quirúrgicas más precisas y eficientes que disminuyan la huella quirúrgica y logren resultados postoperatorios favorables para los pacientes, ha sido el objetivo de la cirugía laparoscópica en el siglo XXI. Con el fin de disminuir el número de heridas quirúrgicas y su morbilidad asociada, se creó la cirugía endoscópica transluminal por orificios naturales 
(NOTES por sus siglas en inglés), siendo ejemplos del desarrollo de esta técnica el enfoque vestibular de tiroidectomía endoscópica transoral (TOETVA), la cirugía mínimamente invasiva transanal (TAMIS) y la cirugía transumbilical endoscópica (U-LEES) (7). Otra técnica novedosa es la cirugía laparoscópica de incisión única (SILS por sus siglas en inglés), que consiste en la utilización de imanes en lugar de incisiones para ubicar los laparoscopios con el fin de transportar endobags, pinzas o especímenes intraabdominales a través de la cavidad abdominal $(1,8)$.

Recientemente se han incorporado mecanismos que incluyen el uso de tecnología láser, como es el caso de la aplicación "what-you-draw-is-what-you-cut" (lo que tú dibujas es lo que tú cortas), que busca obtener mayor precisión durante el procedimiento quirúrgico. ROBIN es otro sistema que también involucra dispositivos laser que se encargan mediante un sensor de la toma de medidas anatómicas guiadas basadas en puntos de referencia específicos, útil en neurocirugía (9). Por otro lado, se busca implementar a mediano plazo la impresión en 3D de los hallazgos preoperatorios en los casos más complejos para facilitar la práctica y preparación de la cirugía. A futuro se espera que cirujanos expertos puedan estar presentes a distancia y participar remotamente en una cirugía acompañando al cirujano principal gracias a la telemedicina $(9,10)$.

En la última década, la cirugía asistida por robot ha logrado convertirse rápidamente en el siguiente paradigma de esta era. Reconocidas escuelas y sociedades a nivel mundial como el colegio americano de cirujanos y la sociedad americana de cirujanos y gastroenterólogos definen la cirugía por sistema robótico como un proceso quirúrgico realizado con alta tecnología que facilita la interacción entre el cirujano y el paciente con objetivos como corregir el defecto humano y potenciar las habilidades del profesional (11). La cirugía robótica nace gracias a un proyecto de gobierno de los Estados Unidos cuyo objetivo era desarrollar un programa de cirugía a distancia que pudiera atender heridos en campo de batalla protegiendo el talento humano en salud con el que se contaba (12). En 1992, en el Reino Unido se presentó el primer asistente mecánico Robodoc para cirugía ortopédica. Hoy en día se cuenta con el modelo Da Vinci Surgical System que ha tenido una progresiva acogida a nivel mundial.

En Colombia, se comenzaron los programas de cirugía robótica alrededor del año 2015 en centros hospitalarios de cuarto nivel. El éxito que ha tenido hasta el momento se debe a la capacidad del asistente robótico para repetir tareas con precisión asegurando así, menor manipulación y mejores desenlaces para el paciente en el postoperatorio.

El cirujano se incorpora lejos del campo estéril a un ambiente virtual, el cual cuenta con un monitor para cada ojo que integra las imágenes tomadas por cámaras independientes. Esta estrategia se traduce en una visión estereoscópica para el cirujano la cual mejora drásticamente la percepción de profundidad. Por otro lado, la reacción háptica (sensación táctil) en los controles permite emular la experiencia táctil del procedimiento quirúrgico. Estos dos elementos principalmente componen el "efecto inmersión" en la cirugía robótica, asegurando así control absoluto e indirecto del procedimiento desde un ambiente más cómodo y tranquilo para su operador $(12,13)$. 


\section{REFERENCIAS}

1. Lau WY, Leow CK, Li AK. History of endoscopic and laparoscopic surgery. World J Surg. mayo de 1997;21(4):444-53.

2. Fleming FJ, Kim MJ, Messing S, Gunzler D, Salloum R, Monson JR. Balancing the risk of postoperative surgical infections: a multivariate analysis of factors associated with laparoscopic appendectomy from the NSQIP database. Ann Surg. diciembre de 2010;252(6):895-900.

3. Ingraham AM, Cohen ME, Bilimoria KY, Pritts TA, Ko CY, Esposito TJ. Comparison of outcomes after laparoscopic versus open appendectomy for acute appendicitis at 222 ACS NSQIP hospitals. Surgery. octubre de 2010;148(4):625-35; discussion 635-637.

4. Coccolini F, Catena F, Pisano M, Gheza F, Fagiuoli S, Di Saverio S, et al. Open versus laparoscopic cholecystectomy in acute cholecystitis. Systematic review and meta-analysis. Int J Surg Lond Engl. junio de 2015;18:196-204.

5. García Ruiz A, Gutiérrez Rodríguez L, Cueto García J. Evolución histórica de la cirugía laparoscópica. Rev Mex Cir Endoscópica. 15 de agosto de 2016;17(2):93-106.

6. Herrera-Esquivel J de J, Patiño-Suárez K, Délano-Alonso R, Valenzuela-Salazar C, Bonilla-Salado A. Evolución de la endoscopía y la cirugía endo/ laparoscópica; pasado, presente y futuro. Rev Mex Cir Endoscópica. 10 de octubre de 2018;19(3):131-6.

7. Fernandez-Ranvier G, Meknat A, Guevara DE, Inabnet WB. Transoral Endoscopic Thyroidectomy Vestibular Approach. JSLS [Internet]. 2019 [citado 12 de junio de 2020];23(4). Disponible en: https://www.ncbi.nlm.nih.gov/pmc/articles/PMC6830499/

8. Ortiz C, Muñoz N, Flórez H, Saavedra S. Colecistectomía transvaginal híbrida y por incisión umbilical única asistida con imanes: serie de casos. Rev Colomb Cir. junio de 2010;25(2):121-30.

9. Martínez-Salamanca JI, Martínez Ballesteros C, Tewari A, Carballido JA. Cirugía robótica y tecnología láser: una oportunidad para descubrir. Arch Esp Urol Ed Impresa. noviembre de 2008;61(9):1157-62.

10. Campero JM, Guzmán S, Kerkebe M, Mercado A. Cirugía laparoscópica en urología: breve reseña histórica y estado actual del arte. Rev Médica Clínica Las Condes. 1 de marzo de 2018;29(2):169-79.

11. Fraga J. Present time of the robotic surgery. Rev Cuba Cirugia. 1 de marzo de 2017;56:50-61.

12. Moreno-Portillo M, Valenzuela-Salazar C, Quiroz-Guadarrama CD, Pachecho-Gahbler C, Rojano-Rodríguez M. Cirugía robótica. Gac Médica México. 15 de enero de 2014;150(Suppl 3):293-7.

13. Pietrabissa A, Vinci A, Pugliese L, Peri A. Cirugia robótica: controversias actuales y expectativas futuras. Cir Esp. febrero de 2013;91(2):67-71. 


\section{Historia de la cirugía laparoscópica}

Autor: (Semillero Cirugia General)

Fuente: Garcia A. et al. Evolución histórica de la cirugía laparoscópica.

Revista de la asociación mexicana de cirugia endoscópica, 2016.

\section{¿Qué es? \\ La laparoscopía es una técnica quirúrgica mínimamente invasiva que puede ser utilizada tanto en diagnóstico como en la terapéutica de un paciente, con el fin}

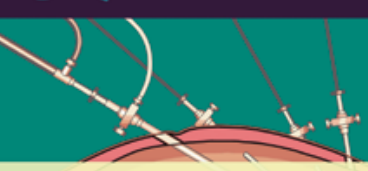

A lo largo del tiempo se han realizado diversos aportes que contribuyeron a crear y perfeccionar la técnica y los instrumentos que conocemos actualmente.

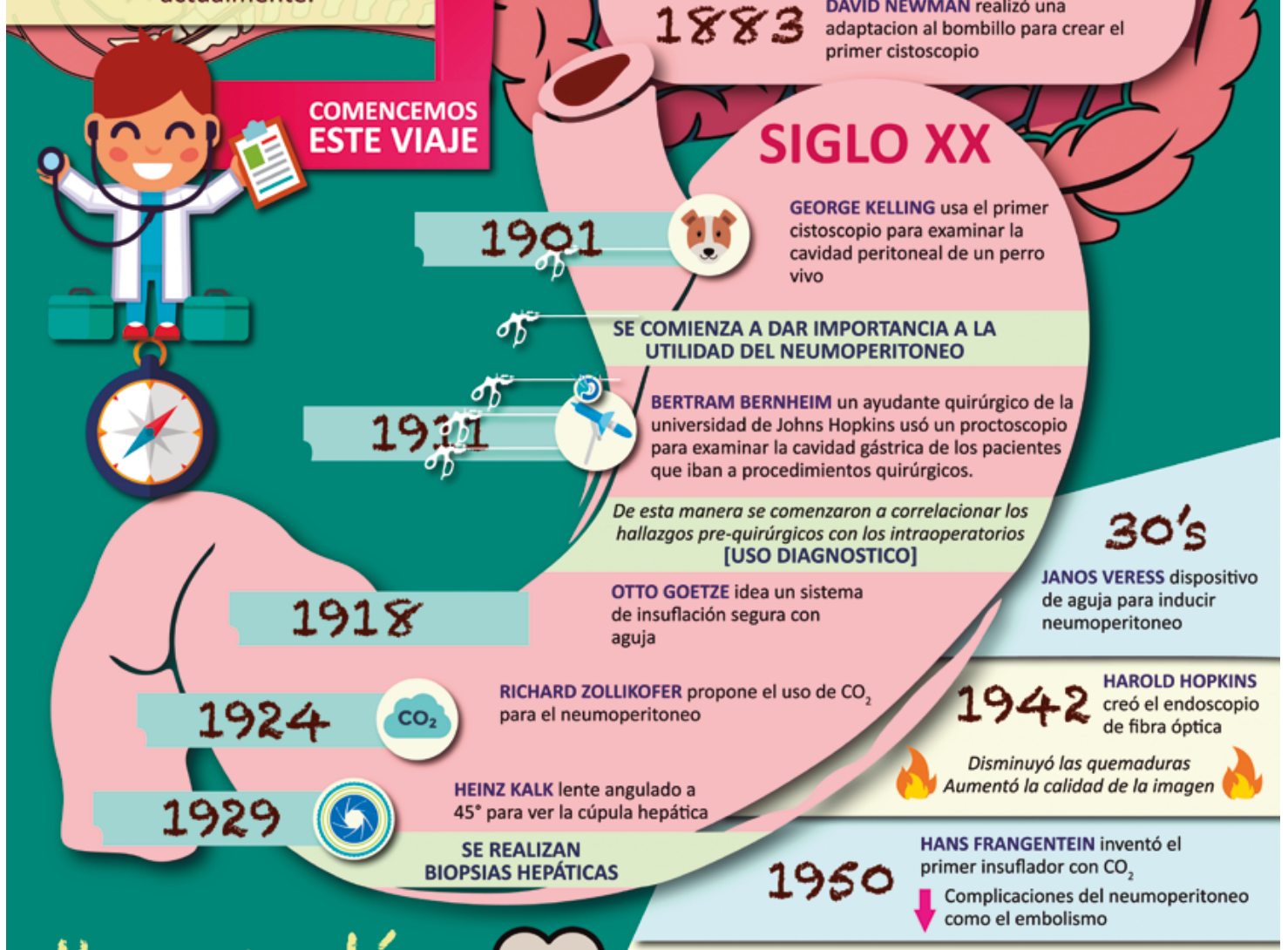

Hoy en día

Continúa un crecimiento exponencial de la técnica laparoscópica, con el fin de encontrar más utilidades y perfeccionar el procedimiento
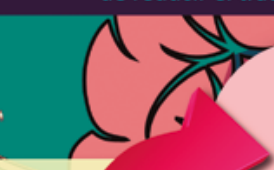

\section{SIGLO XIX}

1 PHILLIP BONZZINI diseñó un sistema luz incandescente mediante el cual observó la uretra de un paciente

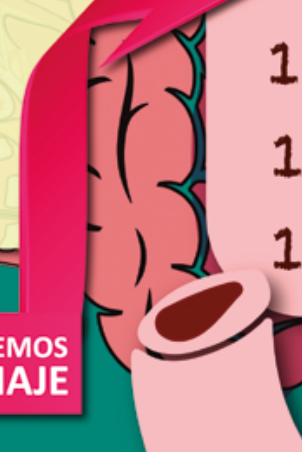

$1 \% 2$ antonin desormeaux

14 creó el primer endoscopio

$18800_{\text {EDISON }}^{\text {THOMAS }}$

DAVID NEWMAN realizó una adaptacion al bombillo para crear $\mathrm{e}$ primer cistoscopio

GEORGE KELLING usa el primer cistoscopio para examinar la cavidad peritoneal de un perro

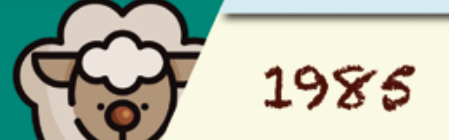

ERICH MÜHE cirujano alemán, realiza la primera versión de una COLECISTECTOMÍA

LAPAROSCÓPICA utilizando un endoscopio modificado al que llamó 'GALLOSCOPIO'

PHILLIPPE MOURET en Francia, documento oficialmente la primera colecistectomía por esta ALDO KLEIMAN argentino, experimentó la colecistectomía en un grupo de ovejas 